\title{
SUSCEPTIBILITY OF IT DEVICES TO HPM PULSE
}

\author{
RAFAE PRZESMYCKI \& MARIAN WNUK \\ Faculty of Electronics, Military University of Technology, Warsaw, Poland.
}

\begin{abstract}
The paper presents method for estimate susceptibility of informatic devices for high-power electromagnetic (HPEM) pulses realized by employees of the LAB-KEM MUT. Susceptibility estimation of IT devices will help you understand the susceptibility level of IT devices on the HPEM pulses environment. This estimation focuses on determining the upper level of the IT devices (PC, notebook, HDD, $\mathrm{SD}$ card, MMC card, Wi-Fi routers and more) in the HPEM environment.
\end{abstract}

Keywords: electromagnetic field, electromagnetic pulse, EMC, HPM, HPEM, IT device, susceptibility.

\section{INTRODUCTION}

The IT infrastructure, personal computers and storage devices are an integral part of our business and everyday life. If you use the IT devices in critical infrastructure or use for the protection, IT security is not acceptable appearance of any disturbances in the electromagnetic environment. In an environment of high-power electromagnetic (HPEM) microwave source is a relatively new kind of risks, both for military and civilian systems. Operation using this type of source is generally referred to as intentional electromagnetic disturbance. HPEM-radiated environment, which is naturally harmful, can also occur at frequencies up to several tens MHz. Generate an HPEM pulse in the direction of the electronic system makes that on the electronic circuits accumulates very high voltage. This phenomenon causes damage to the circuit elements which makes the device unfit for further operation. In the case of a purposeful interaction an impulse is very important in terms of its effectiveness to generate sufficiently strong impulse at the required frequency $[1,2]$.

Comparatively new risks for military and civil systems in the HPEM environment are high-power microwave (HPM) pulses. An attack with this kind of source is typically defined as intentional electromagnetic interference (EMI). Radiated HPEM environments which are malignant in nature can also occur at frequencies down to a few of MHz.

Technological developments within the area of HPMs have made it possible to produce more powerful microwave sources for illuminating large operational installations. At the same time, it is possible to generate relatively strong fields with compact systems that can be contained, e.g. in a briefcase.

The potential threat from HPM has increased. If an HPM system is fielded by a North Atlantic Treaty Organization (NATO) country, there may be a need to harden co-located friendly systems against the fields produced. However, the actual threat that may exist from friendly or hostile sources in any particular scenario has not yet been fully defined by any NATO nation. The information provided below is therefore general and unclassified. National authorities should be consulted to determine if an HPM environment needs to be specified for any particular system or equipment [3].

While the effects of other HPEMs environment like lightning electromagnetic pulse (LEMP) and nuclear electromagnetic pulse (NEMP) have been tested and measurement in the past and characteristics are readily available, HPM is a comparatively new research area. 
Hostile source characteristics are difficult to predict and possible 'friendly' sources are subject to security issues and have yet to be defined in a meaningful manner, which make defining the HPM environment very difficult [3].

Criminals, terrorists, disgruntled employees/customers, hostile military/special forces and competitors are all potential HPM attackers. The potential scenarios are comparable. A disgruntled employee may bring a small, improvised device into the facility to simply cause some trouble. A terrorist may use a truck-mounted source to cause havoc. A military approach may be to use an airborne system to cause damage [3].

The characteristics of the threat environment are limited by the attacker's technical skill, technology level and access to technological means.

The power of radiated HPM sources ranges from KWs to GWs (peak). In general, the frequency ranges from tens of $\mathrm{MHz}$ up to several GHz. Fig. 1 represents a frequency relation between LEMP, NEMP and HPM sources adapted from IEC 61000-2-13 [3].

Depending on the objective and the knowledge of the target, the attacker will select a type of HPM source with the most effective waveform to reach the objective and cause maximum effect. The types of HPM sources and the possible waveforms are described in the standard AECTP250 Edition 2. The energy levels at the location depend on a wide range of parameters.

Informatic and electronic components and devices (e.g. microprocessor boards) are essential parts of modern civil and military systems like communication, IT-infrastructure or safety systems. Since these informatic components began to control safety critical functions, concern grew over the vulnerability of informatic systems. Therefore the susceptibility of critical systems is of vital interest since a setup or failure in these systems could cause major accidents or economic disasters. The increase of non-metallic materials like carbon-fiber composite as well as the decrease of signal levels results in a decreased susceptibility level of informatic systems. As a consequence, the investigation of the susceptibility of electronic systems as well as their protection and hardening against HPM threats is of great interest.

Due to the design and the functionality of informatic, the employed HPEM test environment and the setup of susceptibility tests, the observed effects differ significantly from each other. In addition manufacturers of informatic systems are reluctant to have the susceptibility data of their systems be published and discussed in public.

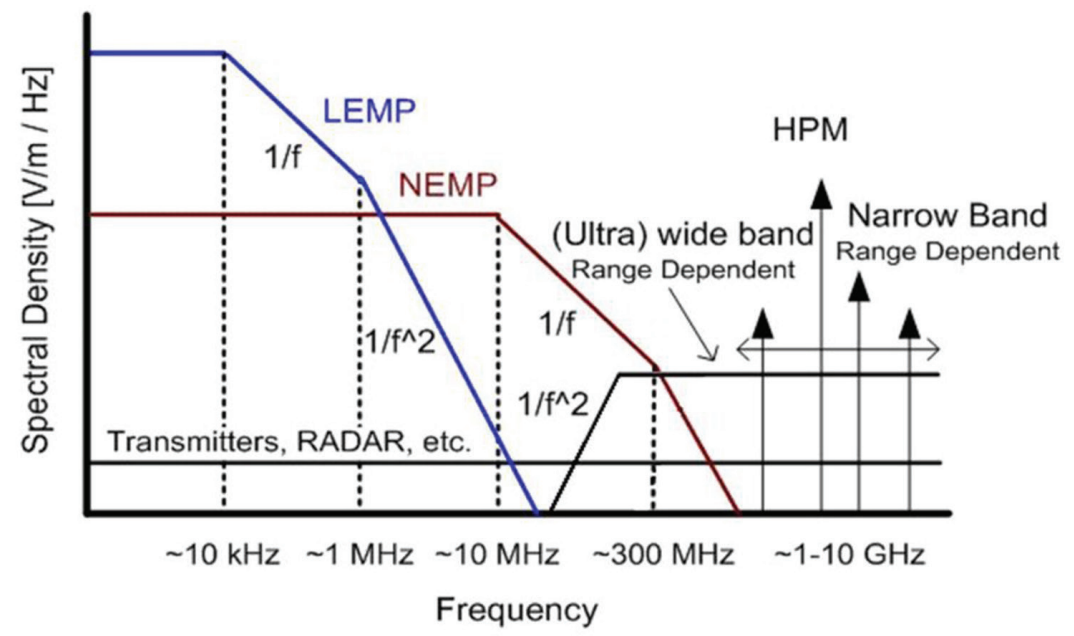

Figure 1: Comparison of Typical High-Power Electromagnetic Environments (HPEM) [3]. 


\section{HIGH POWER ELECTROMAGNETIC PULSE}

HPM pulse is a very short duration pulse (the duration time is a few of nanoseconds) and high power (a few of GWs in pulse).

HPM pulses for the first time were observed as a side effect in outbreaks of atomic bombs, it was also found that the extent of such radiation greatly exceeds the means of destruction yet. Currently, several generation methods of HPM pulse were developed through dedicated generators of electromagnetic radiation. Destructive action of E bombs depends on the destruction of all electronic equipment based on semiconductor technology, and in particular cases of destroying whole infrastructure of communications and power transmission. Fig. 2 shows an appearance of HPM pulse in the time domain, while Fig. 3 shows the frequency spectrum of the pulse $[4,5]$.

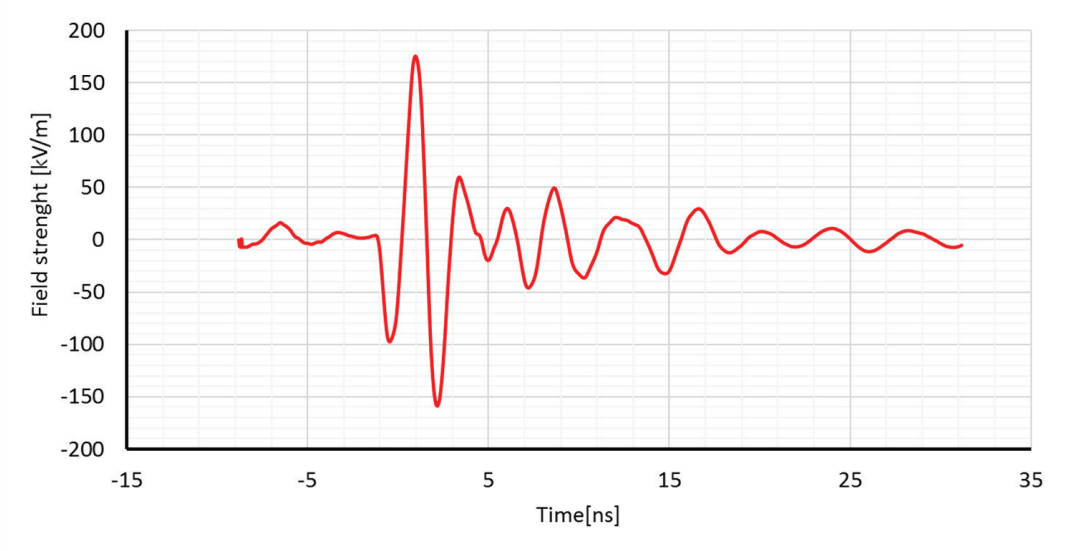

Figure 2: An example of time domain for sample HPM pulse [6].

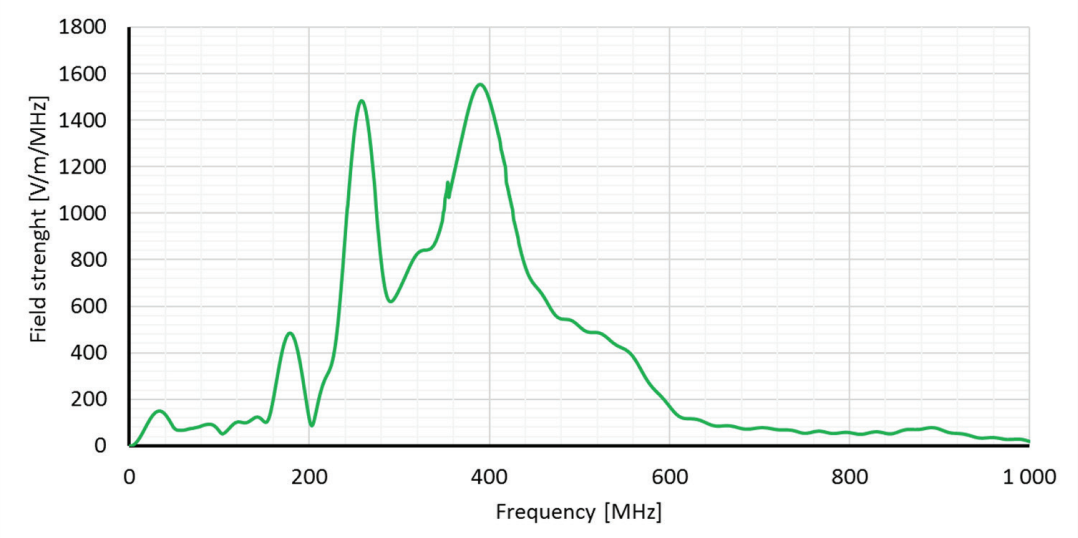

Figure 3: An example of frequency spectrum for sample HPM pulse [6]. 


\section{THE LABORATORY STAND FOR GENERATION AND MEASUREMENT \\ OF HPM PULSE}

The main element responsible for the generation of a HPM pulse is a generator Diehl DS 110, which is shown in Fig. 4. It is compact enclosed equipment, looks like a suitcase. Components of the generator are high-voltage power supply, $300 \mathrm{kV}$ Marx generator and a resonant antenna. High-voltage power supply system supplies the Marx generator by $50 \mathrm{kV}$ voltage (symmetrical voltage $\pm 25 \mathrm{kV}$ ), he is charged until the threshold set by the switch that sets pressure gas $\mathrm{N}_{2}$ in the generator. When changing the position of the switch, antenna is fed a $300 \mathrm{kV}$ voltage, the sparker contained in the air is isolated by the pressure gas $\mathrm{N}_{2}[4,6]$. The basic specification of the HPM DS110F generator is shown in Table 1.

The Diehl Measurement System incorporates a fast digitizing oscilloscope running from an uninterruptible power supply (UPS). The UPS is used in a different manner than originally intended. The UPS operates the oscilloscope for up to 3 hours without mains connection before recharging the batteries of the UPS is required.

Oscilloscope and UPS are installed in a shock damped and electromagnetically shielded housing. This allows not only outdoor measurements without mains available, it also allows
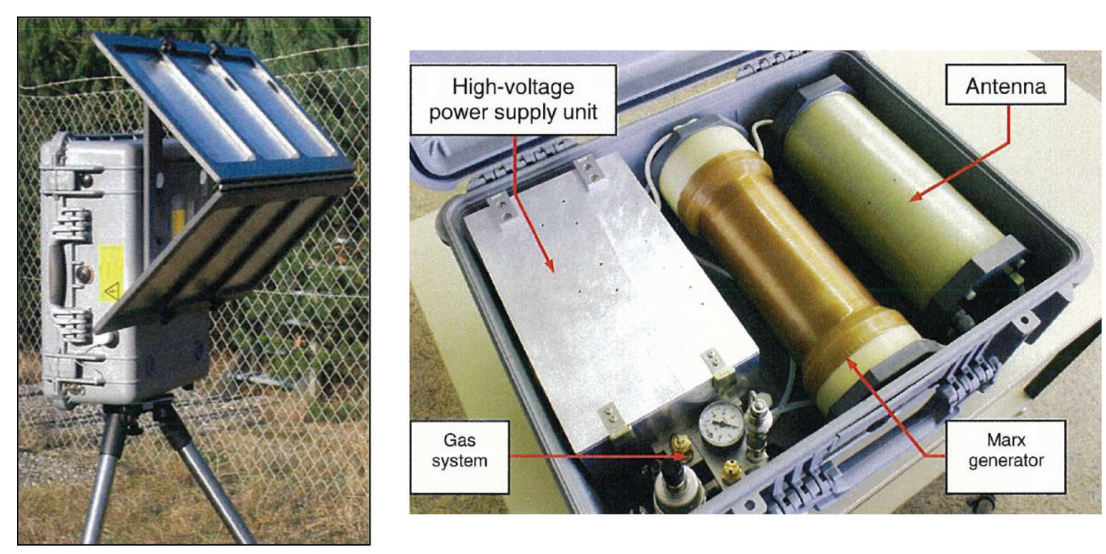

Figure 4: View of the generator Diehl DS 110 [7].

Table 1: DS110F specifications.

\begin{tabular}{ll}
\hline Parameter & Value \\
\hline Size & $500 \times 410 \times 200 \mathrm{~mm}$ \\
Weight & $24 \mathrm{~kg}$ \\
Peak radiated power & $160 \mathrm{MW}$ \\
Radiation pattern (without reflector) & Dipole \\
Pulse duration & $4 \mathrm{~ns}$ \\
Repetition rate & $>5 \mathrm{~Hz}(10 \mathrm{~Hz}$ typ) \\
Centre frequency & $350 \mathrm{MHz}$ \\
3 dB bandwidth & $100 \mathrm{MHz}$ \\
Operating time (without reflector) & $>1 \mathrm{hours}$ \\
\hline
\end{tabular}


shielded measurements without any connection to outer environment except the field measuring probe.

The Diehl Measurement System combines a state of the art Tektronix Digital Phosphor Oscilloscope with a computer UPS and an additional battery pack within a shielded and shock damped housing. Due to this combination the Diehl Measurement System can be operated, e.g. in free field without mains, and it can be operated with closed shielding lids when in close distance to radiating HPM systems. The Diehl Measurement System includes a so-called D-dot probe and a balun which are designed to measure pulsed electromagnetic fields. Within the shielded housing a laptop computer is stored usable to calculate measured electromagnetic fields and to further process measured data.

For measuring fast HPM pulses with the Diehl Measurement System a combination of D-dot probe Prodyn AD-70 and a balun Prodyn BIB-170F was chosen as the optimum free field sensor. The probe is mounted on a plastic stand to reduce measurement influences to minimum. Free field sensors as the Prodyn AD-70 are dual sensors. They have two antenna elements that are sensitive to the same field but measure in opposite directions. They have their own ground reference between the two elements. Electric (D-dot) sensors have capacitive sensing elements in opposite to magnetic (B-dot) sensors having inductive sensing elements or loops. The D-dot sensors measure time derivative of electric displacement. The sensor is passive devices and does not need external power supply. Since the sensor is symmetric a balun is required. Balun is the abbreviation for BALanced and UNbalanced and describes a unit which converts the symmetric probe signals to a common, non-symmetric signal as usual in coaxial cables. The D-dot effective antenna size of $0.001 \mathrm{~m}^{2}$ as well as the balun insertion loss of $8 \mathrm{~dB}$ are included as standard parameters within the Excel macros. These values can be changed in Microsoft Excel worksheet when using other probes than original ones delivered with Diehl Measurement System [7].

The main component of Diehl Measurement System is a state of the art Tektronix Digital Phosphor Oscilloscope DPO70404. It contains four analogue channels each having $4 \mathrm{GHz}$ bandwidth and $25 \mathrm{GS} / \mathrm{s}$ real time sampling rate. For pulsed field measurement of Diehl Measurement System an interpolated higher sampling rate is not usable, the real time sampling method is always to be used. The oscilloscope is mounted into a shielded 19-inch box using the Tektronix Rackmount Kit. The Tektronix DPO70404 incorporates an own computer board for operating the equipment. It would be possible to install Microsoft Excel with processing macros but Diehl experience is that using a separate computer makes the oscilloscope more stable and data analysis more independent. The oscilloscope allows to record so-called FastFrame formats. FastFrame is able to capture many trigger events respectively many HPM pulses as sequential records in a larger single record. It is possible to view and measure each record individually. Time stamps display the absolute trigger time for a specific frame and the relative time between triggers of two specified frames. This means that several HPM pulses can be stored within one file and can be processed in the computer in one step. Data measured with the oscilloscope can be stored either on internal hard disk, on USB sticks connected at back or front USB ports or directly on network drives when connected with other computers. Diehl recommends to store measured data first on internal hard disk. To copy them onto the laptop computer use either USB memory sticks or network connection. This insures that only a duplicate copy is onto the laptop computer when processing measured data [7].

The output of the D-dot sensor is proportional to the first-time derivative of the electric displacement $\mathrm{D}(\mathrm{t})$, that is:

$$
\mathrm{D}-\mathrm{dot}=\mathrm{dD} / \mathrm{dt}
$$


and, rewriting equation:

$$
\mathrm{Vo}=\mathrm{R} \text { Aeq } \mathrm{dD} / \mathrm{dt} \text {, or } \mathrm{dD} / \mathrm{dt}=\mathrm{Vo} / \mathrm{R} \text { Aeq }
$$

then, recalling that $\mathrm{D}=\varepsilon \mathrm{o} \mathrm{E}$,

$$
\mathrm{dE} / \mathrm{dt}=\mathrm{Vo} / \mathrm{R} \text { Aeq } \varepsilon \mathrm{o}
$$

The output of the D-dot sensor is measured in volts that are proportional to units the first time derivative of electric displacement $\mathrm{dD} / \mathrm{dt}$, coulombs per square meter. The constant of proportionality between the sensor output and the first-time derivative of the electric field $\mathrm{dE} / \mathrm{dt}$ (= $\mathrm{dD} / \mathrm{dt} \varepsilon \mathrm{o}$ ) is the permittivity constant $\varepsilon \mathrm{o}$. The constant of proportionality between the sensor output Vo and the first-time derivative of the electric field $\mathrm{dE} / \mathrm{dt}$ is the product of the output impedance $\mathrm{R}$ and the equivalent area Aeq of the sensor, and the permittivity constant $\varepsilon \mathrm{o}$. This is the calibration factor, but it is applied to the first time derivative of the electric field, $\mathrm{dE} / \mathrm{dt}$, not to the electric field itself [8].

The sensor output resulting is a cosine function with amplitude Vop and frequency f, where:

$$
\mathrm{Ep}=1 / 2 \mathrm{f}(\mathrm{dE} / \mathrm{dt}) \mathrm{p}=\mathrm{Vop} / 2 \mathrm{f} \mathrm{R} \text { Aeq } \varepsilon \mathrm{o}
$$

In the sinusoidal or CW case, the peak value of the input field can be obtained from the peak value of the sensor output, the constant of being proportionality being the product of the general constant $\mathrm{R} *$ Aeq o and $2 * \mathrm{f}$, which is constant if the frequency is constant when the measurement is made, as in the $\mathrm{CW}$ case.

A reasonable estimate of the maximum value of $\mathrm{D} / \mathrm{t}$ or $\mathrm{E} / \mathrm{t}$ is obtained by measuring the change in $\mathrm{D}$ or $\mathrm{E}$ over the time interval during which $\mathrm{D}$ or $\mathrm{E}$ is changing most rapidly. This is usually taken as the T/6 duration when D or E is going from +0.5 (Dp or Ep) to -0.5 (Dp or Ep). This is the maximum output we expect from the sensor.

The integrated sensor output is obtained by integrating the sensor output with respect to time. If the sensor output has been digitized, the integral can be obtained easily by multiplying the numerical values of $\mathrm{D} / \mathrm{t}$ by $\mathrm{t}$ over the time interval 0 to $\mathrm{t}$. As the number of discrete points increases, $\mathrm{D} / \mathrm{t}$ becomes a better estimate of $\mathrm{dD} / \mathrm{dt}$ and $(\mathrm{D} / \mathrm{t}) \mathrm{t}$ becomes a better estimate of $\mathrm{dD}=\mathrm{D}=1 /$ Aeq $*$ Vodt [8].

Fig. 4 has been presented a block diagram of the laboratory stand to generation and measurement of HPM pulse. The main elements of this laboratory stand are the Diehl generator and field probe, which they are placed in an anechoic chamber so that the probability of damage other electronic devices located near the generator is very small. In addition, they have been placed on the metal floor with ferrite absorbers thus ensuring that a common reference mass. Devices in the measurement room allow their safe operation by authorized persons $[1,9]$.

Also in this case a common reference mass of the measuring devices is ensured by a protective metal casing. Components of the laboratory stand located in the anechoic chamber arranged in accordance with block diagram of Fig. 5 are shown in Fig. 6.

\section{HPM SUSCEPTIBILITY TESTING}

Estimating the susceptibility levels for the IT equipments is to determine the level of susceptibility to the impact of this device by pulsed electromagnetic field. Estimation of susceptibility levels will be presented on the example of the few chosen IT equipments. We are selected 


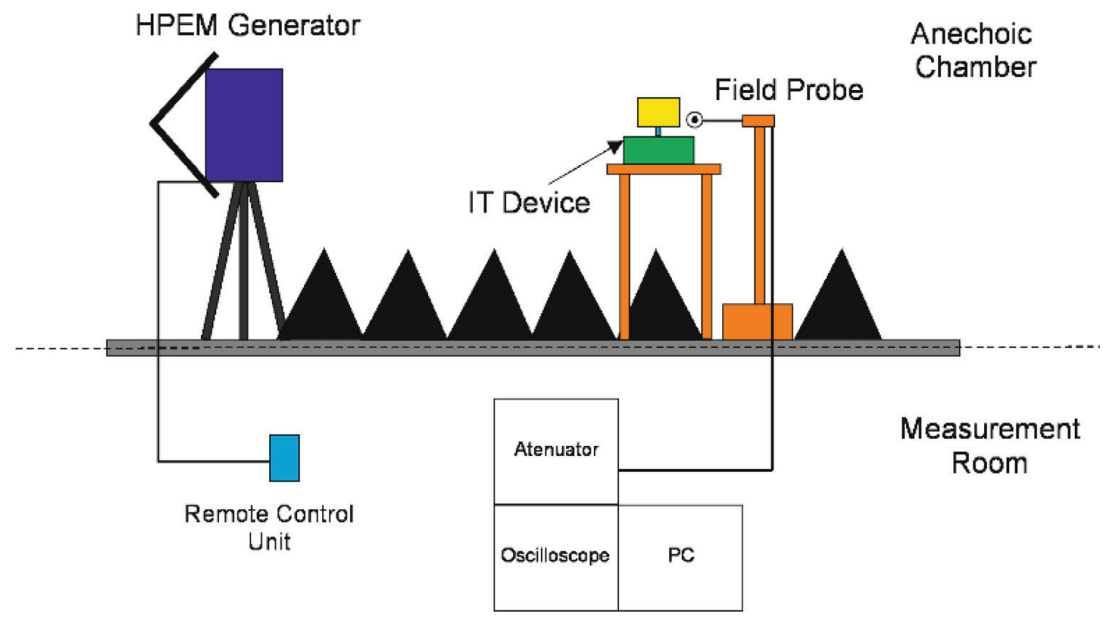

Figure 5: The block diagram of laboratory stand for generating and measurement of HPM pulse.

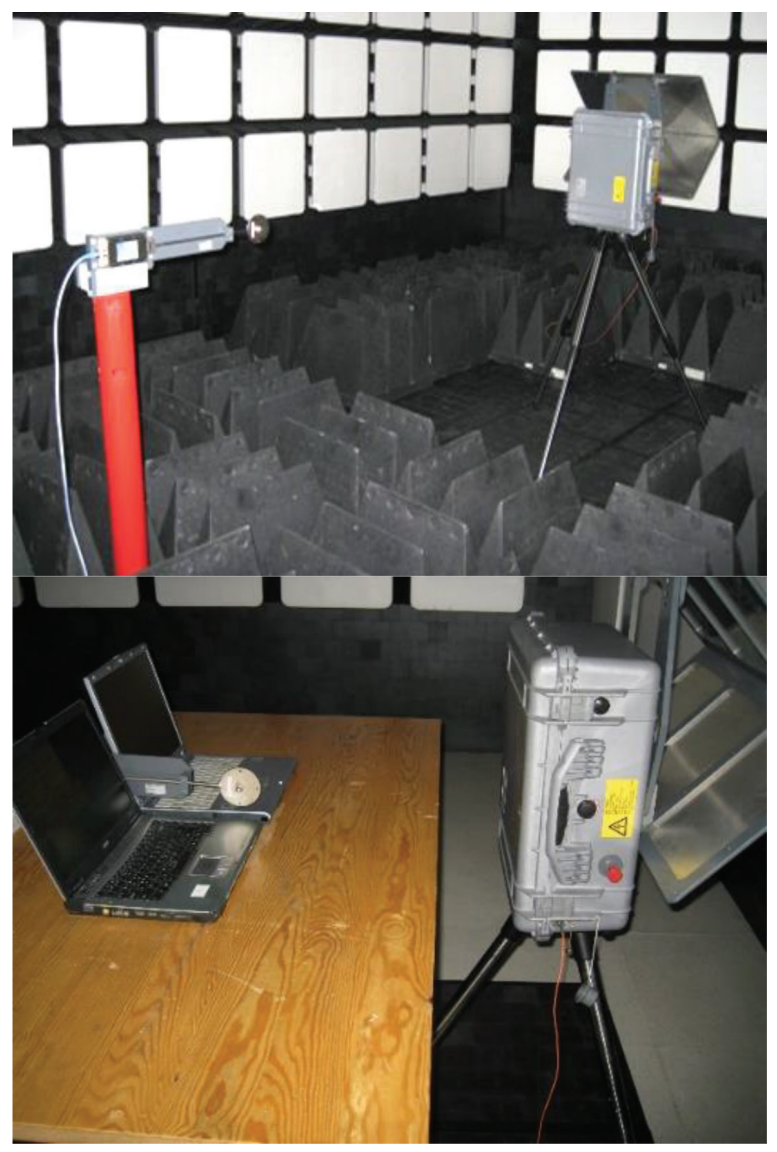

Figure 6: The view of laboratory stand for measurement of HPM pulse. 
notebook computers, tablets, TEMPEST computer and Wi-Fi routers external hard disk, Flash memory and memory cards. For testing was prepared eight notebook computers, four tablets, two TEMPEST computers, two Wi-Fi routers, four hard disks, six memory cards (four SD cards and two MMC cards) and five USB Disk (Flash memory).

Before proceeding to set the level of susceptibility, we must apply to the characteristics of the selected device. The more data we collect about the devices we will more precisely determine the level for fulfillment. When we know the all the elements we can affect the levels of susceptibility/immunity of informatic equipment to the impact pulsed electromagnetic field, we can proceed with the research [1,4].

The measuring process is start from selection of informatics device (PC, tablet, TEMPEST PC) and run or start from writing to all data storage media files with information containing diverse content. In this experiment, data storage media stored text file created in MS Word, the file containing the image in jpeg format, binary file with the extension bin and the file with the recorded film with extension avi. After saving data on individual data storage have been reading validation of individual files on all data storage equipment [1].

Then, the chosen IT device is placed into anechoic chamber, which there is a laboratory stand for generation and measuring of HPM pulse. After placing the IT device into an anechoic chamber we can starts the triggers HPM pulse generator. In the measurements we set to triggering the generator 1 HPM pulses in one second, and 10 HPM pulse in one second. After the process exposing HPM pulses IT device, the device is checked with the other computer is working correctly. When the IT device is damaged and it is impossible to turn on it, we determined immunity level for the IT device on the basis of the generated field strength. In the case where the IT device is working correctly and we can read data stored on device, we put it back into an anechoic chamber, increasing the level of HPM pulse and we release the generator, thereby exposing our IT device by HPM pulses with increased power. After exposure again we check the correct operation of our device. These steps we repeat until we set the susceptibility levels on pulsed electromagnetic field for all tested IT device $[1,4]$.

\section{OBSERVATIONS AND TEST RESULTS}

The study consisted in verifying the behavior of the device information in the high-power pulse electromagnetic field. The investigated object (information device) was placed in an anechoic chamber $80 \mathrm{~cm}$ above the ground and moved away from the HPM generator at different distances, resulting in different field strength [1].

In the experiment the research were subjected to chosen IT devices that shortly characterized in Table 2. The chosen devices were exposed to 1 HPM pulse and 10 HPM pulses. The rest of this article presents only the results of the exposure of IT devices for a 1 pulse, due to the fact that exposures computer equipment for a 10 HPM pulses, the results were identical. It can be concluded that no number of pulses but amplitude of pulse in does case the interference (damage) of the device [1].

Table 3 summarizes the susceptibility of different IT devices on HPEM fields. This table shows the statistics on the number of interference (damage) of the chosen IT devices in relation to the level of intensity HPM pulse. For example, the value of $3 / 5$ indicates that the test were three interference (damage) on a five series of exposures consisting of HPM pulse $[10,11]$.

The statistics concerning a susceptibility of chosen IT device show that most failures were Wi-Fi routers, portable devices (tablets), notebooks and hard disk's, and the least damage is 
Table 2: Characteristics of selected IT devices being tested.

\begin{tabular}{ll}
\hline IT device & Description \\
\hline PC 1 to PC 8 & Notebook computer manufactured in 2015 and 2016 year \\
Tablet 1 to Tablet 4 & Tablets manufactured in 2015 and 2016 year \\
TEMPEST & Two TEMPEST Computers manufactured in 2015 and 2016 year \\
Router 1 and 2 & Router WLAN 54MBits manufactured in 2015 and 2016 year \\
Hard Disk HDD 1 & External Hard Disk Drive 20 GB, USB 2.0 interface with an ad- \\
ditional power cable \\
Hard Disk HDD 2 & External Hard Disk Drive 40 GB, USB 2.0 \\
Hard Disk HDD 3 & External Hard Disk Drive 100 GB, USB 2.0 \\
Hard Disk HDD 4 & External Hard Disk Drive 1 TB, USB 3.0 \\
Memory Card SD 1 & The SD memory card with a capacity of 16 MB \\
Memory Card SD 2 & The SD memory card with a capacity of 16 MB \\
Memory Card SD 3 & The SD memory card with a capacity of 512 MB \\
Memory Card SD 4 & The SD memory card with a capacity of 1 GB \\
Memory Card MMC 1 & The MMC memory card with a capacity of 32 MB \\
Memory Card MMC 2 & The MMC memory card with a capacity of 1 GB \\
USB Disk 1 & External memory type Flash Drive 128 MB \\
USB Disk 2 & External memory type Flash Drive 256 MB \\
USB Disk 3 & External memory type Flash Drive 512 MB \\
USB Disk 4 & External memory type Flash Drive 1 GB \\
USB Disk 5 & External memory type Flash Drive 2 GB \\
\hline
\end{tabular}

Table 3: Test results statistics for selected data storage devices.

\begin{tabular}{lllllllll}
\hline & 10 & 30 & 60 & 80 & 120 & 180 & 250 & 320 \\
& $\mathrm{kV}$ & $\mathrm{kV} / \mathrm{m}$ & $\mathrm{kV} / \mathrm{m}$ & $\mathrm{kV} / \mathrm{m}$ & $\mathrm{kV} / \mathrm{m}$ & $\mathrm{kV} / \mathrm{m}$ & $\mathrm{kV} / \mathrm{m}$ & $\mathrm{kV} / \mathrm{m}$ \\
\hline PC 1 & $0 / 5$ & $3 / 5$ & $4 / 5$ & $5 / 5$ & $5 / 5$ & - & - & - \\
PC 2 & $0 / 5$ & $3 / 5$ & $4 / 5$ & $5 / 5$ & $5 / 5$ & - & - & - \\
PC 3 & $0 / 5$ & $3 / 5$ & $3 / 5$ & $5 / 5$ & $5 / 5$ & $5 / 5$ & - & - \\
PC 4 & $0 / 5$ & $2 / 5$ & $4 / 5$ & $5 / 5$ & $5 / 5$ & $5 / 5$ & - & - \\
PC 5 & $0 / 5$ & $2 / 5$ & $3 / 5$ & $5 / 5$ & $5 / 5$ & - & - & - \\
PC 6 & $0 / 5$ & $2 / 5$ & $3 / 5$ & $5 / 5$ & $5 / 5$ & $5 / 5$ & - & - \\
PC 7 & $0 / 5$ & $3 / 5$ & $4 / 5$ & $5 / 5$ & $5 / 5$ & - & - & - \\
PC 8 & $0 / 5$ & $3 / 5$ & $4 / 5$ & $5 / 5$ & $5 / 5$ & $5 / 5$ & - & - \\
Tablet 1 & $0 / 5$ & $3 / 5$ & $3 / 5$ & $5 / 5$ & $5 / 5$ & - & - & - \\
Tablet 2 & $2 / 5$ & $4 / 5$ & $4 / 5$ & $5 / 5$ & $5 / 5$ & - & - & - \\
Tablet 3 & $1 / 5$ & $3 / 5$ & $4 / 5$ & $5 / 5$ & $5 / 5$ & - & - & - \\
Tablet 4 & $2 / 5$ & $4 / 5$ & $4 / 5$ & $5 / 5$ & $5 / 5$ & - & - & - \\
\hline
\end{tabular}


Table 3: (Continued)

\begin{tabular}{lllllllll}
\hline & 10 & 30 & 60 & 80 & 120 & 180 & 250 & 320 \\
& $\mathrm{kV}$ & $\mathrm{kV} / \mathrm{m}$ & $\mathrm{kV} / \mathrm{m}$ & $\mathrm{kV} / \mathrm{m}$ & $\mathrm{kV} / \mathrm{m}$ & $\mathrm{kV} / \mathrm{m}$ & $\mathrm{kV} / \mathrm{m}$ & $\mathrm{kV} / \mathrm{m}$ \\
\hline TEMPEST 1 & $0 / 5$ & $0 / 5$ & $0 / 5$ & $0 / 5$ & $1 / 5$ & $1 / 5$ & $4 / 5$ & $5 / 5$ \\
TEMPEST 2 & $0 / 5$ & $0 / 5$ & $0 / 5$ & $0 / 5$ & $1 / 5$ & $1 / 5$ & $3 / 5$ & $5 / 5$ \\
Router 1 & $4 / 5$ & - & - & - & - & - & - & - \\
Router 2 & $5 / 5$ & - & - & - & - & - & - & - \\
HDD 1 & $0 / 5$ & $0 / 5$ & $4 / 5$ & $5 / 5$ & $5 / 5$ & - & - & - \\
HDD 2 & $0 / 5$ & $0 / 5$ & $0 / 5$ & $0 / 5$ & $4 / 5$ & $5 / 5$ & $5 / 5$ & - \\
HDD 3 & $0 / 5$ & $0 / 5$ & $0 / 5$ & $0 / 5$ & $4 / 5$ & $5 / 5$ & $5 / 5$ & - \\
HDD 4 & $0 / 5$ & $0 / 5$ & $0 / 5$ & $0 / 5$ & $0 / 5$ & $5 / 5$ & $5 / 5$ & $5 / 5$ \\
SD 1 & $0 / 5$ & $0 / 5$ & $0 / 5$ & $0 / 5$ & $0 / 5$ & $0 / 5$ & $0 / 5$ & $0 / 5$ \\
SD 2 & $0 / 5$ & $0 / 5$ & $0 / 5$ & $0 / 5$ & $0 / 5$ & $0 / 5$ & $0 / 5$ & $0 / 5$ \\
SD 3 & $0 / 5$ & $0 / 5$ & $0 / 5$ & $0 / 5$ & $0 / 5$ & $0 / 5$ & $0 / 5$ & $0 / 5$ \\
SD 4 & $0 / 5$ & $0 / 5$ & $0 / 5$ & $0 / 5$ & $0 / 5$ & $0 / 5$ & $0 / 5$ & $0 / 5$ \\
MMC 1 & $0 / 5$ & $0 / 5$ & $0 / 5$ & $0 / 5$ & $0 / 5$ & $0 / 5$ & $0 / 5$ & $5 / 5$ \\
MMC 2 & $0 / 5$ & $0 / 5$ & $0 / 5$ & $0 / 5$ & $0 / 5$ & $0 / 5$ & $0 / 5$ & $5 / 5$ \\
USB Flash 1 & $0 / 5$ & $0 / 5$ & $0 / 5$ & $0 / 5$ & $0 / 5$ & $1 / 5$ & $1 / 5$ & $1 / 5$ \\
USB Flash 2 & $0 / 5$ & $0 / 5$ & $0 / 5$ & $0 / 5$ & $0 / 5$ & $1 / 5$ & $1 / 5$ & $1 / 5$ \\
USB Flash 3 & $0 / 5$ & $0 / 5$ & $0 / 5$ & $0 / 5$ & $0 / 5$ & $1 / 5$ & $1 / 5$ & $5 / 5$ \\
USB Flash 1 & $0 / 5$ & $0 / 5$ & $0 / 5$ & $0 / 5$ & $0 / 5$ & $1 / 5$ & $1 / 5$ & $5 / 5$ \\
USB Flash 4 & $0 / 5$ & $0 / 5$ & $0 / 5$ & $0 / 5$ & $0 / 5$ & $1 / 5$ & $1 / 5$ & $5 / 5$ \\
USB Flash 5 & $0 / 5$ & $0 / 5$ & $0 / 5$ & $0 / 5$ & $0 / 5$ & $1 / 5$ & $1 / 5$ & $5 / 5$ \\
\hline & & & & & & & &
\end{tabular}

the SD memory card and TEMPEST Computer. Immunity levels for each IT devices are as follows:

- for SD and MMC memory cards - above $320 \mathrm{kV} / \mathrm{m}$,

- for TEMPEST computers - $320 \mathrm{kV} / \mathrm{m}$,

- for flash memory (USB flash drive) $-250 \mathrm{kV} / \mathrm{m}$,

- for notebook computers $-180 \mathrm{kV} / \mathrm{m}$,

- for hard disk's - $170 \mathrm{kV} / \mathrm{m}$,

- for tablets $-120 \mathrm{kV} / \mathrm{m}$,

- for Wi-Fi routers $-30 \mathrm{kV} / \mathrm{m}$.

The results of the statistics also show that the newer media (higher capacity, higher cycle frequency the processor clock) were much less susceptible to interference than the older hardware HPM.

\section{CONCLUSIONS}

The possibility of an attack on information technology equipment which work only on a specific frequency significantly restricts the use of this equipment in critical infrastructure. Generate an electromagnetic pulse located in the working range of informatic devices can 
result burnout internal circuits which will make it will be completely unsuitable for further work. Remember to adequately protect the informatic device [1, 4].

The article presents the susceptibility levels of selected IT devices on exposure of HPM pulses and set immunity levels on HPM pulses of selected IT devices at which the devices have been destroyed.

Please be aware that the results presented in the article are very limited and we should collect a more data before the data presented will be introduced into everyday life. They are also required further research to determine, in more detail, of susceptibility data storage equipment based on a sample consisting of a larger number of devices available on the market.

\section{REFERENCES}

[1] Przesmycki, R., Wnuk, M. \& Bugaj M. - HPEM susceptibility assessment of data storage devices, 2016 21st International Conference on Microwave, Radar and Wireless Communications (MIKON), 9-11 May 2016, Kraków, Poland, Electronic ISBN: 9781-5090-2214-4. https://doi.org/10.1109/MIKON.2016.7492113

[2] Kubacki, R. \& Wnuk, M. - Broń elektromagnetyczna - broń przyszłego pola walki, Nowoczesne technologie systemów uzbrojenia, Red. Z. Mierczyk, WAT, Warszawa, pp. 461-470, 2008.

[3] AECTP 250 Ed.2 2011 : Electrical and electromagnetic environmental conditions, NATO INTERNATIONAL STAFF - DEFENCE INVESTMENT DIVISION, 2011.

[4] Przesmycki, R. \& Wnuk, M. - HPEM susceptibility assessment of informatic devices, Progress in Electromagnetic Research Symposium (PIERS), 8-11 August 2016, Shanghai, China, 978-1-5090-6093-1. https://doi.org/10.1109/PIERS.2016.7734568

[5] Przesmycki, R., Wnuk, M., Nowosielski, L., Piwowarczyk, K. \& Bugaj M., The Shielding Effectiveness Measurement Using High Voltage Pulse Generator, Moscow, Russia, PIERS Proceedings 2012, str. 1449-1452, ISSN 1559-9450.

[6] Przesmycki, R., Nowosielski, L. \& Wnuk, M., Metodologia pomiaru absorpcji materiałów z wykorzystaniem generatora HPEM, Przeglad Telekomunikacyjny, ISSN 1230-3496, NR 8-9/2014, str: 821-827.

[7] DIEHL BGT Defence - Operating and Maintenance Manual for DIEHL DS110. KS2.F.MP1.B (HPM Case System DS110), document No BDB8118952.

[8] Reed Edgel, W., The next Best Thing to Calibration, Functional Testing, Prodyn Aplication note.

[9] Rafał, P., Możliwości zastosowania energii skierowanej do niszczenia urzązeń informatycznych, KSTiT Kraków, Polska 16 - 18.09.2015r., Przegląd Telekomunikacyjny, ISSN 1230-3496, e-ISSN 2449-7487, NR 8-9/2015, str: 1178-1181.

[10]Hoad, R., Lambourne, A. \& Wraight, A., HPEM AND HEMP susceptibility assessments of computer equipment, 17th International Zurich Symposium on Electromagnetic Compatibility, pp. 168-171, 2006.

[11]Brauner, F., Sabath, F. \& Haseborg, J.L., Susceptibility of IT network systems to interferences by HPEM, 978-1-4244-4267-6/09/\$25.00 @2009 IEEE, pages 237-242. 